\title{
A palavra crioulo em discursos sobre a língua de Cabo Verde
}

\author{
Luiza Kátia Andrade Castello Branco (IEL/UNICAMP) ${ }^{1}$
}

Resumo: Em nossa pesquisa de mestrado, observamos que a atual nomeação da língua de Cabo Verde como "crioulo" produz efeitos de sentidos que filiam o imaginário da língua à ideologia da domesticação das línguas reproduzida pelo discurso científico, de um lado, e a uma memória de resistência para os falantes do cabo-verdiano, de outro. Analisamos o discurso sobre a língua para compreender os diferentes processos discursivos aí produzidos pelo encontro de uma memória da(s) língua(s) com relação à história que a(s) constituiu. Realizamos, assim, uma leitura discursiva de arquivos sobre o saber lexicográfico sobre a palavra "crioulo" (séculos XVIII-XXI) e sobre o saber sociolinguístico sobre o conceito "crioulo" (século XX).

Palavras-chave: Análise de Discurso; História das Ideias Linguísticas; Sociolinguística; Línguas crioulas; Línguas de Cabo Verde.

\section{Considerações iniciais}

Em nossa dissertação de mestrado², discutimos a questão das línguas em Cabo Verde a partir da perspectiva da História das Ideias Linguísticas em sua especificidade brasileira (ORLANDI, 2001a) - um campo de saber que articula a história da produção do saber metalinguístico com o processo de constituição da língua nacional, pensando o modo de trabalhar a questão da língua em países de colonização. Nessa discussão, demos visibilidade ao funcionamento da palavra "crioulo" nos discursos sobre a língua de Cabo Verde, produzindo um gesto de interpretação inscrito em práticas de leitura da história propostas pela Análise de Discurso. Interessou-nos, nessa pesquisa, o discurso sobre a língua por ser o lugar em que se dá o encontro entre a(s) memória(s) da(s) língua(s) e a história que a(s) constituiu.

Para compreender a historicidade da língua cabo-verdiana, em sua disputa por espaço de enunciação ${ }^{3}$ (GUIMARÃES, 2005) com a língua

\footnotetext{
1 Mestre em Língua Portuguesa pelo Programa de Pós-Graduação da Universidade Federal Fluminense do Rio de Janeiro, com financiamento da Capes. Doutoranda em Linguística pelo Programa de Pós-Graduação da Universidade Estadual de Campinas (UNICAMP), com financiamento da FAPESP. E-mail: luizakcb@yahoo.com.br

${ }^{2}$ BRANCO, L. K. A. Castello. Historicidade e sentidos: a palavra "crioulo" nos discursos sobre a língua de Cabo Verde. 195f. Dissertação (Mestrado em Língua Portuguesa). Instituto de Letras, Universidade Federal Fluminense (UFF), Niterói, 2007. Orientação da Prof. ${ }^{a}$ Dr. Bethania Sampaio Corrêa Mariani

${ }^{3}$ Espaço de enunciação é entendido como um lugar de disputa em que os sentidos aí constituídos decorrem da própria relação política entre as línguas e seus falantes em seus movimentos
} 
portuguesa, propusemos uma reflexão sobre os discursos lexicográfico e sociolinguístico sobre o termo "crioulo/língua crioula". Considerando a questão da produção de sentido como um processo histórico-discursivo imbricado ao processo de constituição dos sujeitos em suas posições (ORLANDI, 2001b), sob condições de produção materiais específicas, demos visibilidade, em nossos procedimentos analíticos, à compreensão de discursividades que, funcionando pela contradição, disseram do modo como as línguas estabeleciam relações em Cabo Verde.

Para entender melhor as questões que se colocavam, construímos um dispositivo de arquivo com os discursos sobre as ilhas, seus sujeitos e sobre as línguas nelas faladas. Esse arquivo, apesar de extenso e heterogêneo, justificouse por trazer textos que se atravessavam por possuírem regularidade no modo de dizer os sujeitos, suas línguas e os espaços, e, contraditoriamente, por darem a ver diferentes regiões de significação no processo de subjetivação desses sujeitos, de suas línguas, e de seus espaços. Esse conjunto heterogêneo de textos trata da história da língua e do saber produzido sobre ela. Uma parte dele se constituiu no corpus efetivo de análise, que é composto pelo discurso lexicográfico produzido sobre a palavra "crioulo" no contexto dos séculos XVIII a XXI, encontrado em dicionários de Filologia e Linguística e dicionários de línguas - portuguesa (do Brasil e de Portugal), espanhola, inglesa e francesa; e pelo discurso sociolinguístico sobre o conceito "crioulo" introduzido pela Sociolinguística no século XX, encontrado em materiais de Linguística e Sociolinguística e de Filologia de autores brasileiros, portugueses, espanhóis, alemães e americanos.

A outra parte desse arquivo constituiu-se como corpus complementar, sendo composto por: entrevistas feitas com cabo-verdianos estudantes aqui no Brasil (especificamente na cidade do Rio de Janeiro); anais de um ciclo de conferências promovido pela Associação dos Estudantes Cabo-verdianos no estado do Rio de Janeiro, em 2004; constituição da república de Cabo Verde de 1999; programa do ano de 2005 do curso de graduação do ensino do português, língua e literatura da Universidade Jean Piaget de Cabo Verde; textos de notícias sobre a língua cabo-verdiana, a partir de sujeitos músicos, políticos e teóricos da língua publicados na mídia eletrônica cabo-verdiana, portuguesa, e americana; prefácios de gramáticas descritivas da língua caboverdiana elaborada por cabo-verdianos; e livros sobre a história de Cabo Verde e sobre a língua e a cultura cabo-verdianas escritos por cabo-verdianos.

históricos e políticos de confronto, de mistura, de contenção e de interdição (cf. GUIMARÃES, 2005). 


\section{O discurso científico sobre as línguas de Cabo Verde}

Para interpretar o discurso científico, que se pretende isento, neutro, impessoal, é preciso considerar o sujeito do discurso no movente curso da linguagem com seus "já-ditos" e suas formas de representar, entender os processos de produção de sentidos de um discurso que se faz "a partir de condições de produção dadas" em que o sujeito é "situado no interior da relação de forças existentes entre os elementos antagonistas de um campo discursivo dado" (PÊCHEUX, 1997, p. 77)4. O que é dito "deve ser remetido às relações de sentido nas quais é produzido" (Id., Ibid.), constituindo-se numa resposta direta ou indireta a outro discurso.

Ao imbricar-se no encontro da memória com a atualidade, o dizer produz sentidos que se filiam a redes de sentidos determinadas pela relação do sujeito com a língua e com a história e pela experiência simbólica e de mundo do sujeito através da ideologia.

Os efeitos de sentido, devemos dizer, são regularizados por suas repetições, paráfrases no processo discursivo, remetendo a uma memória discursiva que faz parte de um processo histórico resultante de uma disputa de interpretações para os acontecimentos presentes ou já ocorridos (MARIANI, 1996). Assim, essa memória ao reproduzir, repetir, parafrasear os efeitos de sentido, atualiza-os, através de uma formação discursiva, num acontecimento.

Tendo sido termo criado pelo europeu, entre os séculos XV-XVI, durante o processo de colonização das Ilhas de Cabo Verde, os efeitos de memória provocados pelo nome "crioulo" remetem a sentidos que circulam ainda nesse imaginário constitutivo do nome da língua, como o de língua de escravo, de povo dominado, subjugado.

\section{O discurso lexicográfico}

Tomando o dicionário como um discurso sobre a língua que produz saber linguístico num contexto histórico-político determinado, observamos o modo como os dicionários de linguística e filologia registravam, de forma geral, o termo "crioulo". Verificamos que era definido como falares ou línguas resultantes de deturpação, deformação ou simplificação de uma língua de cultura, sempre europeia, ou como produto de uma miscigenação linguística, favorecendo seu caráter híbrido, ao classificar o "crioulo" como, por exemplo, uma língua de substrato ligada a uma língua europeia nacional de superestrato, remetendo, depois, ao falante de forma indireta.

Notamos, na pesquisa, que a grande maioria dos dicionários monolíngues, antes da acepção de "crioulo" como língua, trazia "crioulo"

${ }^{4}$ Grifos do autor. 
como indivíduo, o sujeito determinado pela raça e procedência. Nas definições que apresentamos na dissertação, observamos que é a partir do indivíduo então classificado que esses lexicógrafos passam a definir a língua. Na maior parte dos dicionários, o indivíduo é branco, nascido nas colônias intertropicais e descendente de europeus. No caso dos dicionários brasileiros, há a inclusão da definição do indivíduo também como "negro".

Dentro do verbete "crioulo", a acepção referente ao sentido de língua, como já dissemos, vem normalmente depois da de indivíduo, e é definida como mistura proveniente da junção ou do contato com as línguas europeias sempre lexificadoras, ou então, como dialeto de alguma língua europeia.

A convivência entre as duas acepções (de "crioulo" indivíduo e de "crioulo" língua) não pareceu ser de contraste apesar de o indivíduo ser descrito como de "raça branca" ou "negra", sem miscigenação e a língua falada por ele ser descrita como uma "mistura" de, pelo menos, duas línguas: a "nativa" e a "europeia". Para indivíduo, "crioulo" designa não-miscigenação, raça única, identificável, com origem determinável: europeia ou nativa; para língua, miscigenação, com presença dominante da língua europeia colonizadora. $\mathrm{Na}$ verdade, essa contradição entre pureza e mescla não desestabiliza as definições constantes do corpo do mesmo verbete, porque a concepção de língua dessa posição-sujeito lexicógrafo é a da língua apartada do sujeito, que ele inventa, copia ou aprende, domina e determina.

\section{O discurso sociolinguístico}

No caso do discurso dos linguistas e filólogos, a palavra "crioulo" (e a expressão sinonímica "línguas crioulas") em seus escritos movimenta efeitos de sentido tomados como verdades científicas sobre a língua cabo-verdiana, posto que produzidos a partir de posições-sujeito ocupadas na formação social como cientistas da linguagem conhecidos, respeitados e prestigiados em seus meios acadêmicos.

O aporte teórico da Análise do Discurso permite-nos buscar na/pela materialidade da língua a compreensão do que, no discurso, é lido como homogêneo, mas que se sabe heterogêneo em sua constituição, pois está sempre relacionado a outros discursos, num processo em que se imbricam memória e esquecimento. Assim, sob o efeito da homogeneidade que unifica em um grupo as línguas que 'inexplicavelmente' precisam ser agrupadas - o grupo das "línguas crioulas" sob os rótulos "crioulo" e "línguas crioulas" -, abriga-se uma diversidade de sentidos pelos seus múltiplos modos de construção discursiva da referência que pudemos retraçar na materialidade do corpus.

Denominar representa um dizer ideologicamente marcado, um modo de construir discursivamente $\mathrm{o}(\mathrm{s})$ referente(s), uma forma de significar que se 
organiza na ordem do discurso. Assim, o processo da denominação diz da natureza das relações de força (se de imposição, de silenciamento, de ruptura, por exemplo) em determinada formação social e produz sentidos de acordo com as condições de produção, que fazem sobressair, dentre as formações discursivas, a dominante.

Nos discursos dos filólogos e linguistas sobre a língua cabo-verdiana, consideramos como marcas as denominações dadas às "línguas crioulas", não só porque denominar é prática discursiva constitutiva do discurso científico, nos enunciados definitórios dos dicionários e nos enunciados conceituais e classificatórios em áreas como a Sociolinguística e a Filologia; mas também porque, nessa materialidade linguística, a estrutura parafrástica se inscreve pela repetição, produzindo a variação do mesmo, contendo "o dizível no mesmo espaço do que já está instituído" (ORLANDI, 1988, p. 20).

As denominações dadas às "línguas crioulas" marcam os dizeres sobre as línguas de Cabo Verde com a "repetibilidade que sustenta o interdiscurso" (MARIANI, 1998, p. 53), conduzindo e reatualizando os sentidos para essas línguas de forma a contê-los na dimensão da formação discursiva da colonização europeia do Novo Mundo.

Dessa forma, trazemos parte do material analisado que nos permitiu dar visibilidade ao que compreendemos como repetição, como o diferente no mesmo. Ao lermos denominações sobre "língua crioula" ou "crioulo" como as seguintes:

(a) "[...] os crioulos seriam constituídos por gramática indígena e vocabulário europeu" (ADAM, Lucien, ${ }^{5}$ 1886, p. 5, apud SILVA NETO, 1957, p. 437) [grifos nossos];

(b) "modificações que as línguas cultas da Europa sofreram em terras extraeuropéias, na boca dos povos de civilização inferior, postas em contacto com línguas radicalmente diversas" (VASCONCELOS, 1928, p. 1222, apud SILVA NETO, 1957, p. 435) [grifos nossos];

(c) "tosco meio de intercomunicações, uma algaravia hoje batizada com o nome de 'crioulo"' (SILVA NETO, 1957, p. 432) [grifos nossos];

(d) "Simplesmente o nosso latim é o Português e a língua vulgar é o Crioulo" (VEIGA, 1994, p. 258) [grifos nossos];

(e) "[...] um crioulo é geneticamente um descendente de um pidgin" (MOTA, 1996, p. 526) [grifos nossos],

vemos mobilizados, nesses discursos de temporalidades distintas (período de um século), - portanto, produzidos sob condições de produção distintas -, efeitos de sentido sedimentados, instituídos e legitimados, reorganižados por uma

${ }^{5}$ Les idiomes negro-aryens e tmaléo-aryens. 
memória tecida por uma narratividade (MARIANI, 1998) que fixa o sentido oficial, literal para o referente "língua crioula", 'língua com gramática indígena e vocabulário europeu', 'língua culta europeia modificada por povo de civilização inferior', 'língua radicalmente diversa da europeia', 'tosco meio de intercomunicação', 'algaravia', 'língua vulgar', 'descendente de um pidgin'.

Observar a discursividade dessas denominações, isto é, a relação entre linguagem e história no processo de produção de sentidos para os referentes "língua crioula" e "crioulo", consequentemente, permitiu-nos estabelecer relação entre essa materialidade linguística e a propagação de uma memória histórica, no caso, a de que a 'civilização' europeia é 'superior' e radicalmente diversa da 'civilização' indígena, habitante das terras extra-europeias, e, logo, 'inferior'; donde se conclui que essa língua misturada, apesar de língua culta europeia modificada, é uma 'algaravia', 'vulgar', 'tosca'.

\section{Silêncio e resistência}

Orlandi (2001b, p. 128) nos mostra como nomear implica silenciar. Apesar de ser um espaço supostamente vazio, o silêncio significa multiplamente, pois o não-dito é parte complementar do que é dito. E é justo isso, essa incompletude, essas lacunas, que tornam o discurso coerente como tal pelos efeitos de sentido que produzem em um dado contexto.

Porém, essas zonas de sentido silenciadas não podem ser ocupadas discursivamente por qualquer sujeito, já que esses sentidos são contidos pelo mecanismo do silenciamento, evitando, assim, uma leitura historicizada do discurso. No caso de Cabo Verde, o colonizador ocupa posições discursivas que o colonizado não pode ocupar. As posições que o sujeito colonizado pode ou não ocupar são projetadas a partir das posições do colonizador.

Ressaltar, então, a atual nomeação da língua por "crioulo", e não por qualquer outro nome, remeteu-nos a um funcionamento do silêncio que se traduziu, durante o procedimento de análise, em diferentes processos de significação possibilitando ler de forma historicizada a relação de tensão e convívio das situações linguísticas em Cabo Verde, como, por exemplo:

1) Do ponto de vista do não-cabo-verdiano e também do caboverdiano dizer "crioulo" é não dizer o que não deveria/poderia ser dito - e que faz sentido como aquilo que foi transplantado, o que foi gerado de forma deturpada -, é inscrever a língua na memória do já-dito europeu, do préconstruído. A fala do cabo-verdiano é o já-dito pelo discurso colonialista que a reduz ao discurso do mesmo, não sendo passíveis de distinção o um e o outro.

2) Do ponto de vista do cabo-verdiano, dizer "crioulo" - nome de batismo dado pelo outro e, assumido como metalinguagem cientificadora de uma ideologia do mesmo - é dizer de uma língua sem nome, isto é, 
paradoxalmente, é uma língua com nome que não encontra inscrição na ordem das línguas ditas de cultura e civilização, como a língua portuguesa.

3) Ao mesmo tempo e porque o silêncio trabalha nos limites das diferentes formações discursivas, do ponto de vista do colonizado, dizer "crioulo" é "explodir" o outro discurso, mostrando que nesse discurso há outros, explicitando os processos de significação do silêncio. Assim, o silêncio também produz a resistência.

Apesar de o processo parafrástico do discurso científico ser dominante nos discursos sobre as "línguas crioulas", negativizando-as em relação às línguas europeias, não podemos esquecer que os sentidos são múltiplos, que não há um sentido central, que há sempre outros sentidos possíveis que não perdem "a relação com os outros (implícitos)" (ORLANDI, 1988, p. 21).

Desse modo, em nosso procedimento analítico, pudemos compreender a forma como o linguista cabo-verdiano Eduardo Cardoso, em sua gramática descritiva sobre a variante dialetal da Ilha de São Nicolau, $O$ crioulo da ilha de S. Nicolan de Cabo Verde, de 1990, diz sobre a língua caboverdiana produzindo outros efeitos de sentidos, sentidos de resistência. Em sua descrição, Cardoso faz questão de afastar estruturalmente a língua caboverdiana da língua portuguesa, na tentativa de demonstrar que se trata de outro sistema linguístico, exemplificando sempre com a língua de Cabo Verde os fenômenos descritos.

\section{Observações finais}

Pelas relações de sentidos que as definições dos termos "crioulo" e "língua crioula" estabeleceram com as noções de "língua materna", "língua oficial" e "língua nacional", observamos que essas noções não se recobriam, tendo em vista que, em Cabo Verde, a língua materna não é a oficial, e pode ou não ser considerada como nacional. Esse não-recobrimento se produziu, por um lado, pragmaticamente, pela impossibilidade ou não-necessidade jurídico-administrativa de toda língua ser oficial, e, por outro, politicamente, pela memória cabo-verdiana de uma língua outra, diferente do português, reproduzir um efeito imaginário de continuidade que se textualiza por um viés do "passado comum" que aí ressoa.

Assim, observamos os efeitos de uma memória hegemônica sustentada na ideologia das políticas colonizadoras linguísticas europeias, ainda hoje, buscando organizar os sentidos de modo a tornar homogêneas as línguas (cabo-verdiana e portuguesa) e seus falantes, apesar de filiados a discursividades distintas e a memórias heterogêneas, e dos discursos de resistência. 
Portanto, ao significá-los, a memória da colonização determina-os discursivamente, de um lado, pelo viés da variação linguística, buscando, na materialidade das línguas cabo-verdiana e portuguesa, pontos de semelhança entre elas, para filiar a primeira como "derivada" ou "variante" da segunda apesar de as diferenças fonológicas, morfológicas, sintáticas e lexicais serem suficientemente fortes para problematizar a ideia de variação; e, de outro lado, pelo viés de uma "história comum", buscando filiar o imaginário caboverdiano de nação como sendo Cabo Verde ainda "extensão" de Portugal: povo "irmão" que fala a "mesma" língua, "o" português. Dessa forma, apagando da relação entre nações o conflito, os sentidos do diferente, as contradições, pela via da "fraternidade" que faz perder, nessa relação, o caráter político.

Contudo, sabemos que os sentidos não são evidentes, podem ser sempre outros de acordo com seus processos históricos de constituição. Assim, compreendendo que o nome da língua e a questão do imaginário da língua nacional se imbricam do mesmo modo que língua e sujeito, foi possível pensar, após a compreensão dos processos discursivos, que, pela fluidez dos sentidos de "crioulo", materializa-se a questão do desejo e da necessidade cabo-verdiana de autorizar-se como nação que, em seu imaginário, dialeticamente já está e não está formada.

\section{Referências}

CARDOSO, Eduardo Augusto. O crioulo da ilha de S. Nicolau de Cabo Verde. Lisboa: Instituto de Cultura e Língua Portuguesa; Praia: Instituto Cabo-verdiano do Livro, 1990.

COUTO, Hildo. Introdução ao estudo das línguas crioulas e pídgins. Brasília: Editora da Universidade de Brasília, 1996.

GUIMARÃES, Eduardo. Semântica do acontecimento: um estudo enunciativo da designação. Campinas, SP: Pontes, 2005.

MARIANI, Bethania. O PCB e a imprensa: os comunistas no imaginário dos jornais (1922-1989). Rio de Janeiro: Revan, 1998.

. Linguagem e história (ou discutindo a lingüística e chegando à análise do discurso). Cadernos de Letras da UFF, Niterói: Instituto de Letras/ UFF, no 12, p. 13-23, 1996.

MOTA, Ma Antonia C. da. Línguas em contato. In: FARIA, Isabel Hub et al. (org.). Introdução à lingüística geral e portuguesa. Coleção Universitária, Série Lingüística. Lisboa: Editorial Caminho, 1996. p. 505- 533.

ORLANDI, Eni. (Org.). Apresentação. In:

História das idéias

lingüísticas: construção do saber metalingüístico e constituição da língua nacional. Campinas, SP \& Cárceres, MT: Pontes \& Unemat Editora, 2001a. 
Discurso e texto: formação e circulação dos sentidos. Campinas, SP: Pontes, 2001b.

. Discurso e leitura. São Paulo: Cortez, 1988.

PÊCHEUX, Michel. Análise automática do discurso (AAD-69). Trad. E. Orlandi. In: HAK, T. e GADET, F. (orgs.). Por uma análise automática do discurso: uma introdução à obra de Michel Pêcheux. 3. ed. Campinas, SP: Ed. da UNICAMP, 1997.

SILVA NETO, Serafim da. História da língua portuguesa. Rio de Janeiro: Presença, 1957.

VEIGA, Manuel. A sementeira. Portugal: Editor ALAC, 1994. 